\title{
Application of Tools for Creating Maps of Knowledge in Teaching Materials Science to Students of University of Life Sciences
}

\author{
Monika Krzywicka $^{1 *}$, Dariusz Dobrowolski ${ }^{2 \dagger}$, Jerzy Grudziński ${ }^{1 \ddagger}$ \\ ${ }^{1}$ Faculty of Production Engineering, University of Life Sciences, \\ ul. Akademicka 13, 20-950 Lublin, Poland \\ ${ }^{2}$ Institute of Computer Science, Maria Curie-Sklodowska University, \\ pl. M. Curie-Sklodowskiej 5, 20-031 Lublin, Poland
}

\begin{abstract}
Modern distance education systems allow for teaching any subject. However, conducting classes strictly defined by a system of educational cycle, does not always allow for selecting individual learning paths based on knowledge already possessed by the student. Knowledge maps can navigate the content of subject taught by well-defined paths of learning, the course of which may be determined by the student. The article presents an example of using knowledge maps created in the InfoRapid KnowledgeMap system and the results of preliminary studies on the use of training software in English based on maps of knowledge for teaching students of Materials Engineering.
\end{abstract}

Keywords: knowledge maps, knowledge management, e-learning

\section{Introduction - knowledge maps as a tool to support education}

Tony and Barry Buzan [1] created the mind map technique in 1974. Davies defines a mind map as a visual, non-linear network of concepts related to each other [2]. Mind maps are widely used both in the economy (to create a business presentation, projects, or while "brainstorming"), agriculture (the organization of crops), as well as at various levels of education. In primary school, knowledge maps are used, among others, to learn spelling, while at higher levels of education - to prepare summaries, lecture notes; also knowledge maps can be an alternative to the linear notes [3]. Crowe and Sheppard suggest that mind maps can be used as a teaching strategy and can be helpful in supervising and guiding the students while performing various studies [4].

The advantages of mind maps are [3] [1] :

- individual, transparent, easier to remember form,

- unlimited associations with the concept,

- uninhibited structure,

- information is organized in a hierarchical manner.

\footnotetext{
*monika.gruszecka@up.lublin.pl

${ }^{\dagger}$ dariusz.dobrowolski@umcs.lublin.pl

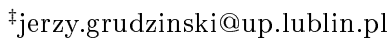

In addition, Race and Pickford indicate that the mind maps are individually prepared by students; this may reduce plagiarism that in recent years has become a serious problem of universities around the world [5]. Multisensory nature of the mind maps facilitates the conversion of information from short to long periods of memory [6]. Meaningful learning outcomes are achieved when the knowledge gained to date is combined with new information [1]. Davies also points out that the mind maps require more active involvement of the students, which contributes to more intensive learning and better results [2]. With mind maps, students who have different learning styles can benefit (visual, kinesthetic)[7]. Traditional methods of education are often not effective due to the top-imposed way of acquiring knowledge, and ignoring the fact that each of us has a different dominant cerebral hemisphere [3]. For education to be effective one must use the two cerebral hemispheres [8]. With traditional learning techniques only the left hemisphere is involved, while the mind maps stimulate both cerebral hemispheres [8] [1]. The integration of both hemispheres accelerates and streamlines the process of learning [3].

The disadvantages of mind maps include: limiting the information to simple associations, the lack of clear links between ideas, inconsistency in the level of detail, difficulty in reading, and sometimes they can also be too complicated [1]. D'Antoni et al., conducted a study on a group of students. Before the exam one group received traditional notes for learning, and the other group - the mind maps. There were no significant differences in average exam results [7]. However, further study is needed to analyze the impact of the use of mind maps for long-term memory. Mind maps can help reduce the time spent on 
preparing for the exam and help you organize information [8]. Mind maps can be prepared manually or using the openly available on-line tools.

\section{IT tools used to create knowledge maps}

There is no a single best way of mapping knowledge. It is possible to create boards with marked sources of knowledge and sets and flows forming on them, indicating the possibility of using tools to allow for drawing the more complex networks. The final shape of a particular map is determined by a number of decisions, such as 1) the subject of maps, 2) the choice of a presentation of information, or even 3 ) the purpose for which knowledge map is created. Therefore, the structure of maps that identify the sources of knowledge, referred to as the topography of knowledge, allows creation of characteristics of the areas of competence of employees, identification of experts in the area and helps with choosing the persons relevant to the implementation of the planned activities.

Among these IT tools that support the process of creating knowledge maps, there can be distinguished such programs as CmapTools, Visual Understanding Environment, InfoRapid KnowledgeMap . They are used worldwide in all fields of knowledge.

(1) The software package CmapTools is an environment that enables the creation and sharing of knowledge-based conceptual maps (Cmaps). CmapTools program itself is simple to use, but has a powerful mechanism by which users can control access to their maps and resources. CmapTools can be used both in education, knowledge management, to brainstorm and to organize information [Fig.1].

(2) Visual Understanding Environment (VUE) is an Open Source project created at Tufts University. The VUE project is focused on creating flexible tools for managing and integrating digital resources in support of teaching, learning and research. VUE provides a flexible visual environment for the structure, presentation and exchange of digital information [Fig.2].

(3) InfoRapid KnowledgeMap is a complete knowledge management system which consists of two components: an image-editing (drawing) program for creating graphically sophisticated mindmaps, and the intelligent KnowledgeMap server, which analyzes text document content and integrates it with a knowledge map. The program can be used not only by students to create maps of knowledge, but also in companies to create organizational charts, decision trees, work breakdown structure or while brainstorming. In addition, the effects of work can be published on the Internet, printed or inserted into programs such as PowerPoint. KnowledgeMap Server allows importing text documents or their analysis and summarises them in the form of a knowledge map. The program is also a tool for collecting full-text information [12]. Using InfoRapid KnowledgeMap allows the student in a very fast and simple way to create knowledge maps, which can be a form of a summary of a particular material [Fig.3].The program allows creating any number of relationships between concepts, it is also possible to insert descriptions that appear only by moving the mouse cursor on the particular subject matter, so that knowledge maps are clear and legible and only the information we are using currently is displayed.

\section{Methodology and results}

In view of the deteriorating teaching outcomes of the Materials Science course among the students at the University of Life Sciences in Lublin, measures have been taken to improve the acquisition of knowledge and increase the attractiveness of classes. The mind maps are an alternative to traditional notes. Using the IT tools in the laboratory classes to create mind maps could facilitate the students the acquisition of knowledge and remembering of concepts and presented phenomena taking place in materials under the influence of technological factors. The example of application of the InfoRapid KnowledgeMap software for the description of the classification, properties and applications of aluminum alloys is shown in Figure 3. The prerequisite for the success of such a venture is students' acceptance for a new form of taking notes during lectures and classes, their basic computer skills and knowledge of English language to the extent allowing the use of the software in English. The recent national survey results indicate continuous growth in IT knowledge among young people. Also the teaching experience of the authors indicates that this knowledge is superficial, mainly limited to the use of basic functions of the Internet and word processing programs. Similar concerns refer to the knowledge of English language which is the most commonly chosen subject in the school-leaving examinations. The study aimed at examining whether the knowledge and abilities of the first year students of the five majors of study at the University of Life Sciences in Lublin would allow the use of English-language education software based on maps of knowledge for teaching Materials Engineering. 


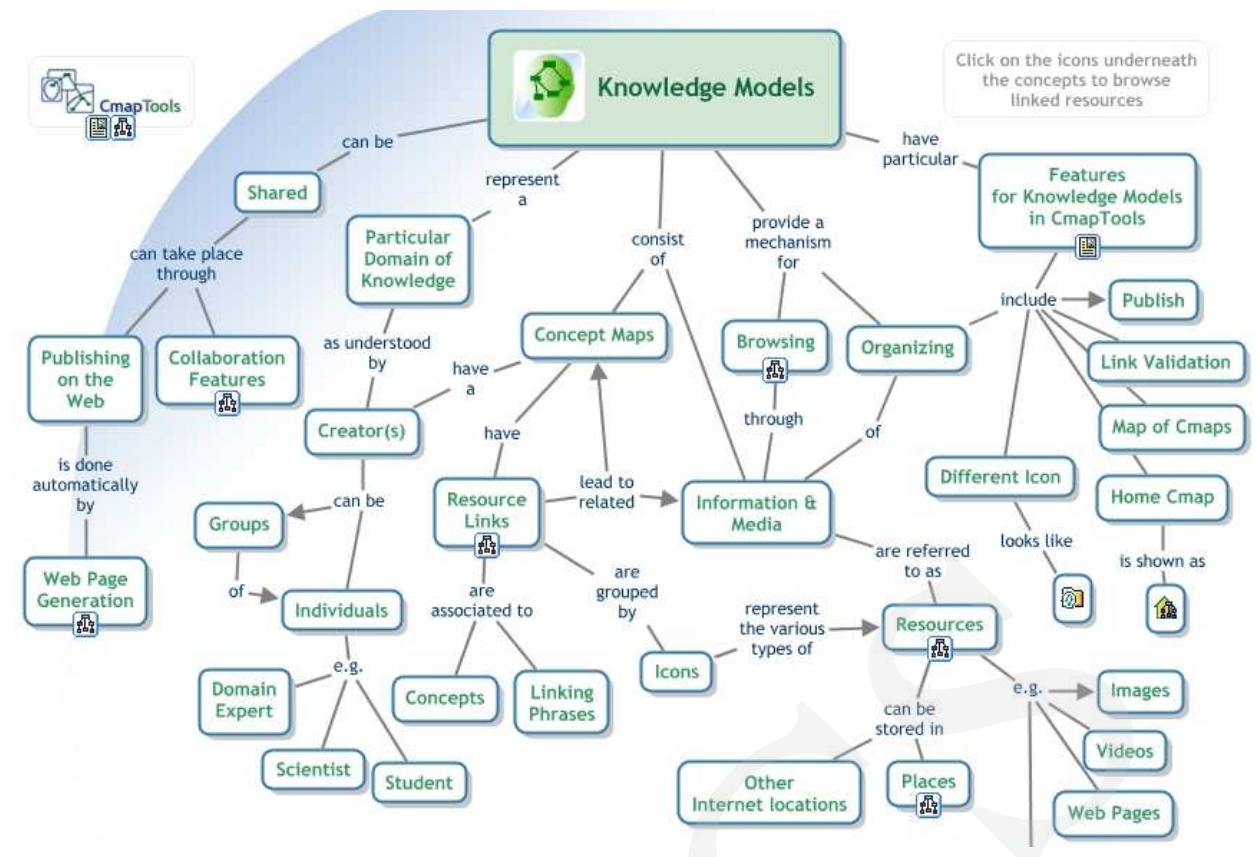

Figure 1. Exemplary screenshot of CmapTools program. (Source: http://cmap.ihmc.us/)

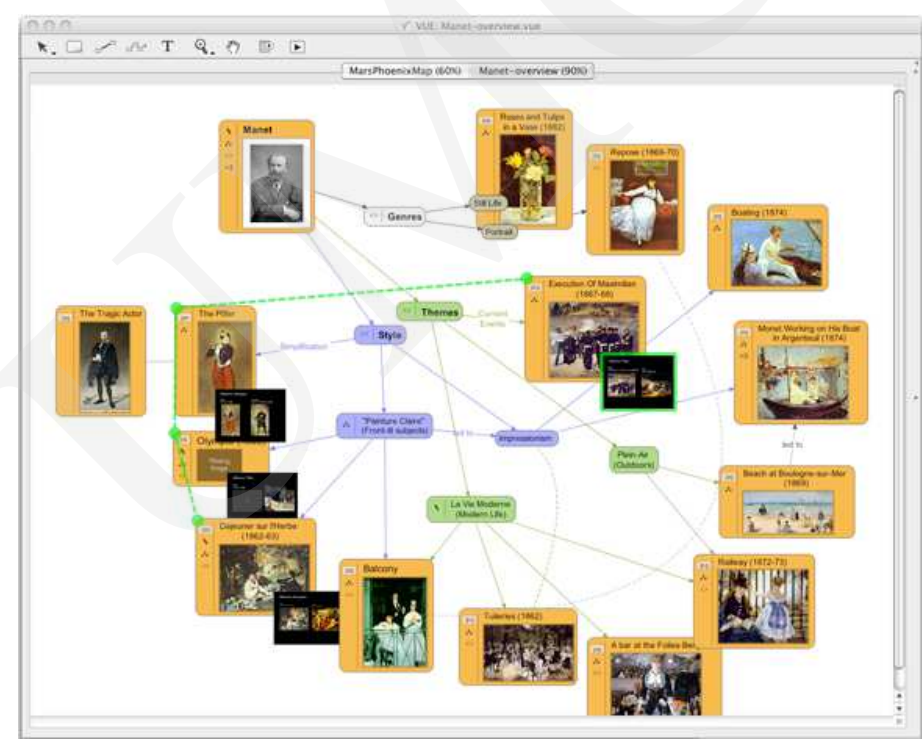

FIGURE 2. Exemplary screenshot of the VUE program (Source: http://vue.tufts.edu/gallery/index.cfm

In order to verify the validity of the hypothesis of changes in the curriculum in 2013, a survey was conducted in a group of 221 students of the first year majors: Agriculture and Forest Engineering (8\% of respondents), Management and Production Engineering (29\% of respondents), Transportation (22\% of respondents), Environmental Engineering (20\% of respondents), Safety Engineering (21\% of respondents). The survey contained 17 questions: personal, on a subjective assessment of English language proficiency, computer literacy, verifying questions, exploring the motivation of students for learning Materials Science, access and acceptance to the use of IT technology. Research has shown that students appreciate the use of IT technology in the classroom and
$76 \%$ of them believe that it raises the attractiveness of classes [Fig.4].

As much as $75 \%$ of respondents would like to know the properties and applications of materials using the computer program [Fig.5].

The above opinions are consistent with the results of research carried out by Bzowska-Bakalarz et al., [9] among the graduates of the University of Life Sciences in Lublin indicating that the graduates see the need of increasing the amount of classes in computer science and foreign languages. Computer-aided education leads to the development of imagination, research activity and creativity of students of technical studies (The role of information technology in academic technical education, 2012). The 


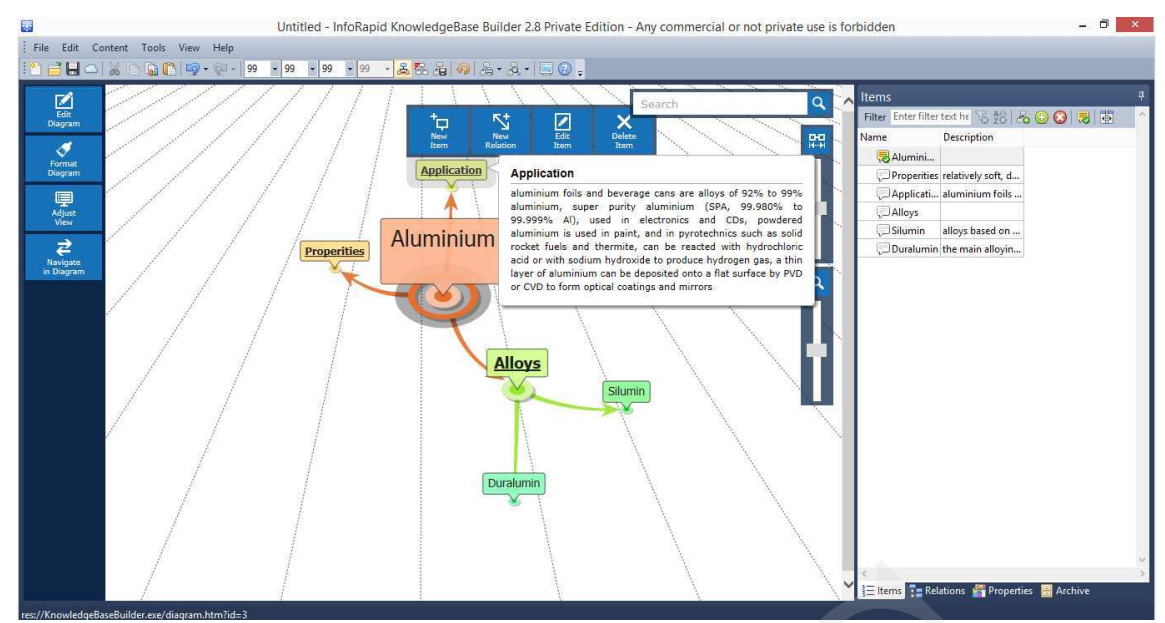

Figure 3. Example of knowledge map for the Materials Science course(Source: Own)

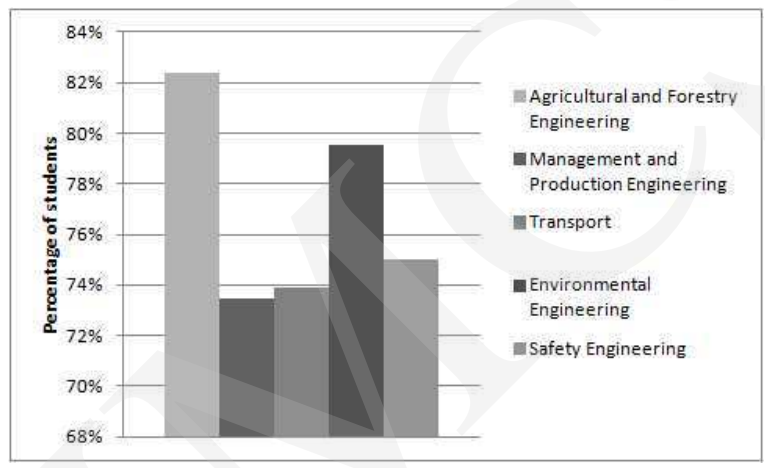

Figure 4. Percentage of students who believe that the use of a computer during the laboratory classes will increase their attractiveness.

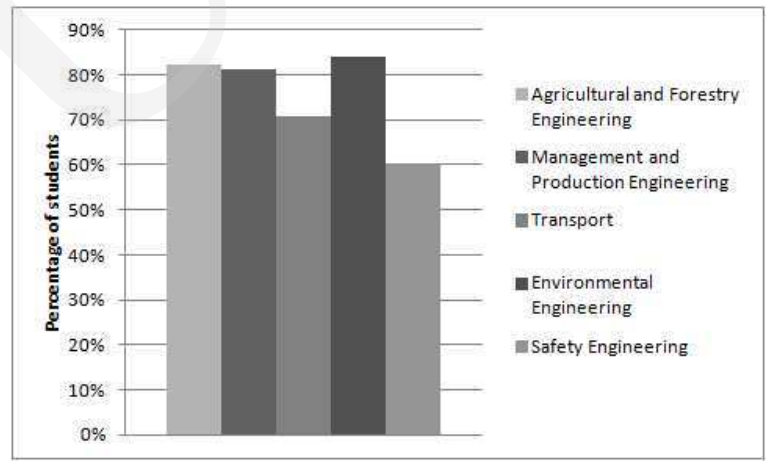

FiguRE 5. Students using the computer program would like to know what factors determine the choice of materials, e.g. for mobile phones.

participants of kinaesthetic-type of classes achieved better learning outcomes than those of visual-type classes, such as lectures [11].

The students were also asked about their subjective assessment of computer skills (on a scale $1-5$, where 1 - poor skills, 5 - very good skills). On average, $56 \%$ of respondents assess their computer skills to be good or very good. In the authors' opinion, the use of the InfoRapid KnowledgeMap software is intuitive and comparable in terms of required skills with the word processing program. [Table 1].

Students indicate that the most attractive classes for them are those with the use of various forms of teaching. When analyzing the results of the study it can be concluded that changes in the curriculum and the use of information technology in the classroom is needed and would increase the attractiveness of classes.

Despite the common use of English words and phrases in everyday speech, only $29 \%$ of respondents assess their 


\begin{tabular}{|c|c|c|c|c|c|}
\hline \multirow{2}{*}{ Respondents/Major } & \multicolumn{5}{|c|}{ Score } \\
\cline { 2 - 6 } & 1 & 2 & 3 & 4 & 5 \\
\hline $\begin{array}{c}\text { Agricultural and Forestry } \\
\text { Engineering, TRiL }\end{array}$ & $0 \%$ & $18 \%$ & $12 \%$ & $52 \%$ & $18 \%$ \\
\hline $\begin{array}{c}\text { Management and Production } \\
\text { Engineering, ZilP }\end{array}$ & $0 \%$ & $3 \%$ & $33 \%$ & $47 \%$ & $17 \%$ \\
\hline Transport, Tr & $0 \%$ & $6 \%$ & $26 \%$ & $48 \%$ & $20 \%$ \\
\hline $\begin{array}{c}\text { Environmental } \\
\text { Engineering, IS }\end{array}$ & $0 \%$ & $7 \%$ & $52 \%$ & $39 \%$ & $2 \%$ \\
\hline $\begin{array}{c}\text { Safety } \\
\text { Engineering, IB }\end{array}$ & $2 \%$ & $10 \%$ & $45 \%$ & $30 \%$ & $13 \%$ \\
\hline Total & $0.5 \%$ & $7.3 \%$ & $36.2 \%$ & $42.2 \%$ & $13.8 \%$ \\
\hline
\end{tabular}

TABLE 1. Subjective assessment of computer skills.

knowledge of English to be good or very good. Therefore, although the handling of the InfoRapid KnowledgeMap software requires knowledge only of basic English phrases, the language factor may hinder the use of sources in English language in the didactic process. [Table 2].

\begin{tabular}{|c|c|c|c|c|c|}
\hline \multirow{2}{*}{ Respondents/Major } & \multicolumn{5}{|c|}{ Score } \\
\cline { 2 - 6 } & 1 & 2 & 3 & 4 & 5 \\
\hline $\begin{array}{c}\text { Agricultural and Forestry } \\
\text { Engineering, TRiL }\end{array}$ & $0 \%$ & $24 \%$ & $41 \%$ & $35 \%$ & $0 \%$ \\
\hline $\begin{array}{c}\text { Management and Production } \\
\text { Engineering, ZilP }\end{array}$ & $5 \%$ & $20 \%$ & $51 \%$ & $19 \%$ & $5 \%$ \\
\hline Transport, Tr & $0 \%$ & $12 \%$ & $48 \%$ & $38 \%$ & $2 \%$ \\
\hline $\begin{array}{c}\text { Environmental } \\
\text { Engineering, IS }\end{array}$ & $0 \%$ & $15 \%$ & $63 \%$ & $15 \%$ & $7 \%$ \\
\hline $\begin{array}{c}\text { Safety } \\
\text { Engineering, IB }\end{array}$ & $10 \%$ & $23 \%$ & $38 \%$ & $19 \%$ & $10 \%$ \\
\hline Total & $4 \%$ & $18 \%$ & $49 \%$ & $23 \%$ & $6 \%$ \\
\hline
\end{tabular}

TABLE 2. Subjective assessment of English knowledge.

\section{Conclusions}

(1) The research has indicated that students appreciate the use of IT methods in the classroom and $76 \%$ of them believe that it improves the attractiveness of classes.

(2) Our observations and results of the survey indicate that $75 \%$ of respondents interest in the issues related to Materials Science.

(3) Approximately $56 \%$ of respondents assess their computer skills to be good or very good and $71 \%$ of them believe that their knowledge of English is at sufficient or poorer level.

(4) Further studies will be aimed at the assessment of selected software for developing knowledge maps by students as an auxiliary teaching method in terms of attractiveness and impact on learning outcomes in Materials Engineering.

\section{References}

[1] Noonan M. 2013. Mind maps: Enhancing midwerify education. Nurse Education Today. 2013, 33, s. 847-852.

[2] Davies M. 2011. Concept mapping, mind mapping and argument mapping: what are the differences and do they matter? Higher Education. 2011, Tom 62, 3, s. 279-301.

[3] Marian M. 2008. Mnemotechnika i mapy myśli jako narzędzia wspomagające proces uczenia się. Zeszyty Naukowe WSOWL. 2008, Tom 4, 150, s. 91-103.

[4] Crowe M., Sheppard L. 2012. Mind Mapping Research Methods. Quality and Quantity. 2012, Tom 46, 5, s. 1493-1504.

[5] Race P., Pickford R. 2007. Making Teaching Work 'Teaching Smarter' in Post-Compulsory education. London : Sage, 2007.

[6] D'Antoni A. V., Pinto Zipp G. i Olson V. G. 2009. Interrater Reliability of the Mind Map Assessment Rubric in a Cohort of Medical Students. BMC Medical Education. 2009, Tom 9, 19.

[7] D'Antoni, A. V.; Pinto Zipp, G.; Olson, V. G.; Cahill, T. F. 2010. Does the Mind Map Learning Strategy Facilitate Information Retrieval and Critical Thinking in Medical Students? BMC Medical Education. 2010, Tom 10, 61.

[8] Buzan T. 2003. Use Your Memory. Edinburgh : BBC Active., 2003.

[9] Bzowska-Bakalarz M., Pieczykolan E. 2005. Jakość kształcenia w ocenie absolwentów Wydziału Techniki Rolniczej. Inżynieria Rolnicza. 2005, Tom 6, 66, strony 65-74.

[10] Kozielska M. 2012. Rola technologii informacyjnych w akademickim kształceniu technicznym. Kraków : Uniwersytet Pedagogiczny w Krakowie, 2012.

[11] Dunn R., Griggs S. A. 2000. Practical Approach to Using Learning Styles in Higher Education. Wesport : Bergin \& Garvey, 2000 .

[12] Inforapid KnowledgeMap. Inforapid KnowledgeMap. [Online] $2014 \quad 05$ 2014. [Cit: $23 \quad 05$ 2014.] http://www.inforapid.de/html/knowledgemapeng.htm. 